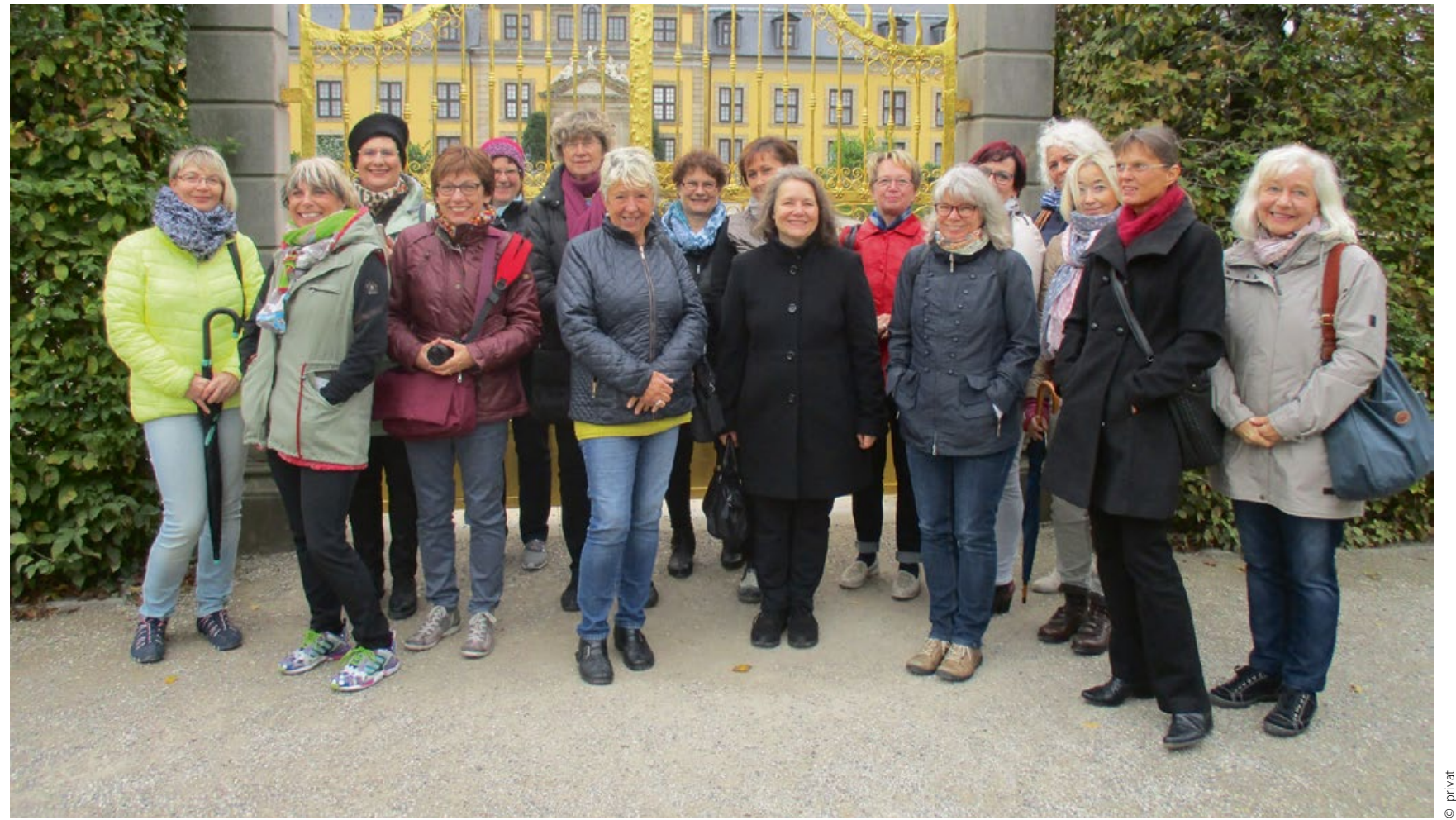

Partner und Mitarbeiter der Landesgeschäftsstellen erkundeten die Sehenswürdigkeiten von Hannover.

Herbstliches Rahmenprogramm zur Hauptversammlung

\title{
Auf den Spuren der Welfen in den Herrenhäuser Gärten
}

Während den Delegierten der FVDZ-Hauptversammlung bei politischen Debatten im Airport Hotel schon vormittags die Köpfe qualmten, gab es für mitgereiste Partner und Mitarbeiter der Landesgeschäftsstellen ein Rahmenprogramm an der frischen Luft der niedersächsischen Landeshauptstadt. Der Bus startete ebenso früh wie die Sitzungen. Ziel der Fahrt: die Herrenhäuser Gärten in Hannover.

Der Busfahrer scherzte schon vor dem Start bei seinen Erklärungen über Anschnallpflicht und die zusätzlichen Funktionen seines Gefährtes. Sogleich regte sich Heiterkeit bei allen. In dieser Stimmung ging es den ganzen Tag weiter. Während wir durch die Herrenhäuser Gärten wanderten, konnten wir den Prunk der Vergangenheit und seine Wiederherstellung nach dem Krieg bewundern. Die gerade vergangene Blütenpracht des Sommers war noch zu erahnen. Obwohl es nicht sehr warm war, konnten die niedrigen Temperaturen unserer fröhlichen Stimmung nichts anhaben.

Bei der Führung durch die barocken Welten der Herrenhäuser Gärten erfuhren wir einiges über das Adelsgeschlecht der Welfen, Sophie von Hannover und ihren Zeitgenossen, dem Universalgelehrten Gottfried Wilhelm Leibniz. Auch waren wir in der Grotte, die nach den Ideen der französisch-schweizerischen Künstlerin Niki de Saint Phalle gestaltet wurde, die für ihre Nana-Figuren bekannt wurde. Getreu dem Motto der Hauptversammlung „Klarheit in den Worten, Brauchbarkeit in den Sachen" (Leibniz), haben auch wir den barocken Garten Hannovers genossen, der sich ebenso vielfältig präsentierte wie unsere sechzehn Bundesländer, klar in der Erscheinung, brauchbar zur Erholung und zur geistigen Erbauung.

Am nächsten Tag gingen die Diskussionen der Hauptversammlung weiter, und nochmals fand sich eine Gruppe zur Erkundung der Landeshauptstadt ein. Diesmal stand die Innenstadt von Hannover auf dem Programm. Die Vielfalt der Erscheinungen der zahlreichen Bundesländer zeigte sich durch siebzehn Frauen. Es war amüsant, etwas über andere und das jeweilige Land zu erfahren. Schlussendlich stellte sich heraus, dass wir überall die gleichen Wünsche haben: Umständlich war gestern! 